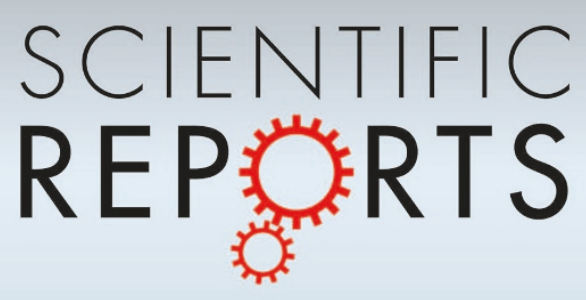

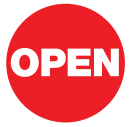

SUBJECT AREAS:

ATMOSPHERIC

DYNAMICS

PROJECTION AND PREDICTION

CRYOSPHERIC SCIENCE

CLIMATE AND EARTH SYSTEM MODELLING

Received

21 December 2012

Accepted

11 March 2013

Published

27 March 2013

Correspondence and requests for materials should be addressed to R.B. (bintanja@knmi.

nl)

\section{The changing seasonal climate in the Arctic}

\author{
R. Bintanja \& E. C. van der Linden
}

Royal Netherlands Meteorological Institute (KNMI), Wilhelminalaan 10, 3732 GK De Bilt, The Netherlands.

Ongoing and projected greenhouse warming clearly manifests itself in the Arctic regions, which warm faster than any other part of the world. One of the key features of amplified Arctic warming concerns Arctic winter warming $(\mathrm{AWW})$, which exceeds summer warming by at least a factor of 4 . Here we use observation-driven reanalyses and state-of-the-art climate models in a variety of standardised climate change simulations to show that AWW is strongly linked to winter sea ice retreat through the associated release of surplus ocean heat gained in summer through the ice-albedo feedback $(\sim 25 \%)$, and to infrared radiation feedbacks $(\sim 75 \%)$. Arctic summer warming is surprisingly modest, even after summer sea ice has completely disappeared. Quantifying the seasonally varying changes in Arctic temperature and sea ice and the associated feedbacks helps to more accurately quantify the likelihood of Arctic's climate changes, and to assess their impact on local ecosystems and socio-economic activities.

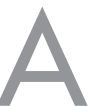
mplified Arctic warming has long been predicted by climate models of varying degrees of complexity ${ }^{1-3}$ as being one of the key features of anthropogenically-induced global warming ${ }^{4}$. Recently, observations confirmed that the Arctic has warmed faster than the rest of the globe during the last few decades ${ }^{5}$, with a very pronounced seasonality as winter warming far exceeds summer warming ${ }^{6,7}$ in conjuction with sea ice retreat $^{8,9}$. The warming appears to be mainly a surface-based feature, especially in the non-summer seasons $s^{6,10}$, even though there is also evidence of summer warming aloft ${ }^{10}$. Arctic warming seems to be linked mainly to sea ice decline $^{6}$, but changes in atmospheric and oceanic heat and moisture transports also play a role ${ }^{11,12}$. The observed and projected changes in the seasonal temperature cycle will have a profound impact on the growth, feeding habits and reproduction activities of flora and fauna and will as such pose challenges to Arctic ecosystems ${ }^{13}$. Moreover, seasonal Arctic warming and the concurrent sea ice retreat ${ }^{6}$ will strongly affect economic activities, with potentially valuable opportunities emerging for transport (shipping), fishery and oil drilling. Arctic warming also impacts the mass balance of glaciers and ice cap ${ }^{14}$, with robust and long-lasting effects on global eustatic and local sea level. Hence, it is imperative to quantify future changes in the Arctic's seasonal temperature and sea ice cycles and to identify the responsible climate mechanisms.

Both observations and model simulations have shown that, when the climate warms, AWW is (considerably) larger than summer warming ${ }^{5,15}$. Three main reasons have been proposed to explain the huge change in seasonal temperature cycle. 1) The greenhouse forcing varies seasonally. If the direct wintertime radiative forcing is much larger than in summer, this could explain the strong AWW. However, greenhouse forcing is relatively uniform over the seasons ${ }^{16}$, hence seasonal variations in direct forcing are too small to explain the huge seasonal swings in Arctic temperature change. 2) Local amplifying feedbacks exhibit seasonal variation ${ }^{17}$. If amplifying feedbacks during winter are much stronger than in summer, this would lead to strong AWW compared to summer. Various feedbacks affect the Arctic's climate response, which complicates a straightforward analysis. There are good indications that Arctic feedbacks indeed exhibit strong seasonal variations ${ }^{17,18} .3$ ) Physical limits may constrain temperature changes, the most prominent of which being melting sea ice keeping the near-surface temperature close to the freezing temperature of sea water. This 'melting sea ice' constraint is commonly put forward to explain the very weak observed and modelled surface temperature changes in Arctic summer (which currently is mostly at the melting point). It implicitly assumes, however, that if Arctic summer temperatures were not near melting, summer warming would be much stronger.

\section{Results}

Here we present results from reanalyses data and from an ensemble of state-of-the-art high-resolution coupled climate models in a variety of standardised climate change simulations in the framework of the Climate Model Intercomparison Project phase 5 (CMIP5, see Methods) ${ }^{19,20}$ to elucidate the seasonally varying 
trends in surface air temperature, sea ice and surface energy budget. Most CMIP5 climate models underestimate Arctic winter warming over the past two decades as compared to reanalyses data and observations, and overestimate summer warming (see Supplementary Information). This indicates that the ratio of (projected) Arctic winter and summer trends is most likely underestimated by climate models. The magnitude of simulated $21^{\text {st }}$ century temperature trends in Arctic winter vary considerably between models (Fig. 1a) - although on average they peak over the Arctic Ocean (Fig. 1b, insert). The ratio of winter and summer temperature trends $(\Psi)$ is largely invariant of the magnitude of the applied forcing (Fig. 1b), however, suggesting that the seasonal change in Arctic temperature is an inherent feature of climate models. The intermodel mean of $\Psi(4.1 \pm 0.9 \mathrm{~K})$, shows that, according to the CMIP5 climate models, Arctic winters will warm about 4 times as fast as summers over the $21^{\text {st }}$ century, irrespective of the magnitude of climate forcing.

Model output reveals a strong correspondence between seasonal warming and sea ice decline in the sense that amplified AWW occurs as long as winter sea ice decreases (Fig. 2, in which we use model 1 as an example); enhanced open ocean increases the upward infrared and turbulent fluxes to warm the winter atmosphere ${ }^{21}$. When all sea ice has disappeared the annual Arctic temperature amplitude has reduced by more than $50 \%$. There is a good intermodel correlation between the timings of winter sea ice disappearing and the change in temperature trend, with sea ice leading (Fig. 2b, insert). Hence, AWW virtually halts once all winter sea ice has disappeared, suggesting that the driving force behind AWW is winter sea ice decline. It should be noted that the increase in forcing in RCP8.5 ends in the year 2200. We believe that this cannot be the main cause of change in AWW increase, since 1) we do not see a similar change in summer temperature trend, and 2) some models predict the timing of the change in temperature trend well before 2200 . Winter sea ice volume exhibits a gradual decline (Fig. 2b) under the specified radiative forcing scenarios, even though the intermodel spread in sea ice volume decline is quite large (Fig. 3a). Reduced sea ice and more exposed open ocean (up to 8 months in 2100, see Fig. 3b) enhances the thermal inertia of the Arctic ocean-atmosphere system, causing the annual Arctic temperature cycle to exhibit a progressively increasing lag to insolation (Supplementary Information).

In Arctic summer, the picture is completely different. Simulated Arctic summer sea ice vanishes quickly in all models, disappearing in $2066 \pm 13$ and $2080 \pm 21$ (multimodel means and standard deviations) for the intermediate and strong forcing scenarios (RCP4.5 and RCP8.5, respectively). (Climate models generally underestimate the recent sea ice decline ${ }^{22}$, in particular in summer ${ }^{20}$ ). Arctic summer temperatures increase very slowly (Fig. 2a), with no apparent change in the trend once summer sea ice vanishes (they remain much smaller than winter temperature trends). Hence, the commonly accepted theory that Arctic summer temperature trends are subdued by the presence of melting ice appears invalid (at least it is not the governing factor), since summer temperature trends do not exhibit a strong post-sea-ice increase that one would expect if this theory were true. This suggests that there are other reasons why Arctic summer exhibits only moderate warming.

Do the seasonally varying Arctic sea-ice-related feedbacks ${ }^{7,18,23}$ play a key role in determining the seasonal temperature response? The ice albedo feedback ${ }^{8,24}$ has long been considered the primary contributor to Arctic warming. This feedback mechanism operates primarily in summer when insolation is highest, and is absent in winter. It can affect wintertime temperature by seasonal storage and release of energy ${ }^{6,15}$, but the actual energy going into summer ocean warming and into ice melt and how much both contribute to heat release in winter (and hence to AWW) remains unclear. Also, the warming Arctic atmosphere has been found to increase downwelling infrared radiation mainly through changes in clouds ${ }^{6}$ and their properties ${ }^{25}$, inversion strength ${ }^{26,27}$ and moisture content ${ }^{7}$. The water vapour feedback involves either increased local evaporation owing to the retreating sea ice ${ }^{28}$ or increased poleward latent heat transport ${ }^{17}$. Another potential contributor to polar warming is increased oceanic heat transport ${ }^{29}$.

It has been argued that changes in the seasonal cycle of oceanatmosphere heat fluxes contribute to $\mathrm{AWW}^{6,8,9,15}$. In summer, the net solar flux into the Arctic ocean increases due to sea ice retreat by virtue of the ice-albedo feedback ${ }^{3,24,30}$; the additional energy is used partly to melt away sea ice and partly warm the ocean (see Supplementary Information). Since summer atmosphere warming is weak, both are carried over to winter during which the warmer ocean opposes sea ice growth. The seasonal 'cycling' of energy is characterised here by annually accumulated positive (downward) surface energy fluxes $\left(\mathrm{SEB}^{+}\right)$and negative (upward) surface energy fluxes $\left(\mathrm{SEB}^{-}\right)$(see Methods). Storage (mainly in summer) and release (mainly in winter) of energy in the Arctic Ocean both depend strongly on sea ice cover (and to a lesser extent sea ice thickness), with its insulating properties regulating wintertime release of heat to the overlying atmosphere ${ }^{21}$. Both storage and release consistently increase in magnitude, indicative of an intensifying Arctic seasonal energy cycle.

Currently, the simulated intraseasonal cycling (i.e. storage/ release) of energy from summer to winter $\left(\mathrm{SEB}^{+}\right)$equals $21 \pm$ $3 \mathrm{~W} \mathrm{~m}^{-2}$ according to the CMIP5 models (2006-2015 average, $\mathrm{RCP} 8.5)$; this is projected to increase by $12 \pm 4 \mathrm{~W} \mathrm{~m}^{-2}$ over the next century under the strong forcing scenario (RCP8.5) (Fig. 4a), an increase of more than $50 \%$. This means that the energy gain in mainly the summer period (primarily shortwave radiation), which increases over time largely because of the ice-albedo feedback, is released in winter, thereby contributing to AWW. In other words, the increase in summertime ocean energy content reinforces winter ocean warming and thereby opposes freezing of seasonal sea ice, which both contribute, directly and indirectly, to increase the upward surface energy fluxes $\left(\mathrm{SEB}^{+}\right)$that warm the wintertime lower atmosphere.

The other important term causing additional heating of the Arctic winter ocean surface is the downward infrared radiative flux ${ }^{17,28,30}$ $\left(\mathrm{LW}_{\text {down }}\right)$. We demonstrated that winter sea ice retreat dictates AWW (Fig. 2 and Fig. 3a, insert), implying that augmented winter warming by any of the infrared components must occur through its interaction with sea ice retreat. As for clouds and atmospheric water vapour, the feedback involving sea ice retreat operates primarily through enhanced evaporation by the increasingly open ocean (which peaks in fall), enhancing both clouds and atmospheric water vapour and thereby $\mathrm{LW}_{\text {down }}$ (ref. 28). The effects of changes in inversion strength indeed peak in locations where sea ice has retreated ${ }^{26,27}$. Hence, the governing infrared radiation components all have strong correspondence to wintertime sea ice retreat.

The central question now is: how much do the summer ice-albedo feedback and the winter infrared feedbacks contribute to AWW? A breakdown of the trends (Fig. 4b) suggests that the shortwave feedback contributes about $+3 \mathrm{~W} \mathrm{~m}^{-2}$ per $100 \mathrm{yr}$ to atmospheric warming, whereas the non-shorwave feedback (mainly infrared) contributes $+9 \mathrm{~W} \mathrm{~m}^{-2}$ per $100 \mathrm{yr}$. These individual trends were determined from the relationship between the various winter flux trends and the summer shortwave flux trend (Fig. 5) among the various CMIP5 models. The linear fits allow to determine the (hypotetical) situation of a shortwave trend of zero (no ice-albedo feedback), when all AWW is thus due to nonshortwave feedbacks. These trends are shown in Fig. $4 \mathrm{~b}$ for the non-shortwave case (right), while the remainder (difference between 'total' and 'non-shortwave') is then equal to the shortwave case (left). The summer ice-albedo feedback thus contributes about $25 \%$ to AWW, through warming of the ocean and by reducing sea ice, and the winter infrared and turbulent fluxes. 

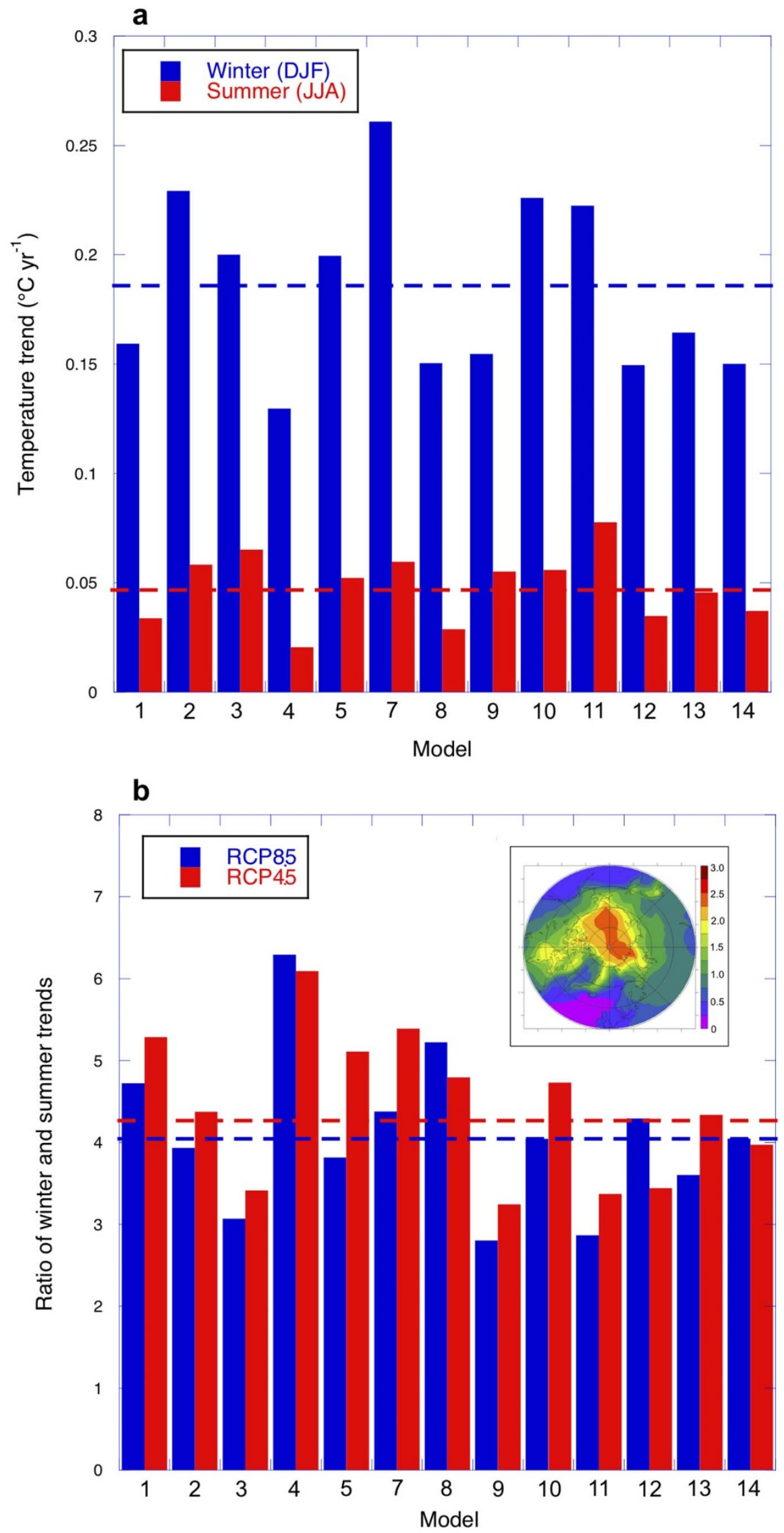

Figure $1 \mid$ Multimodel winter (DJF) and summer (JJA) temperature trends in the Arctic $\left(70^{\circ}-90^{\circ} \mathrm{N}\right)$ during $2006-2100$ for the RCP8.5 and RCP4.5 forcings (see methods). (a) Winter and summer trends for each model for RCP8.5, and (b) Ratio of winter and summer temperature trends for RCP4.5 and RCP8.5 (the insert shows the spatial distribution of the model mean winter temperature trend (in ${ }^{\circ} \mathrm{C}$ per decade) for the RCP8.5 forcing). The horizontal dashed lines denote the model mean values. Models are designated by their number (see Methods). 

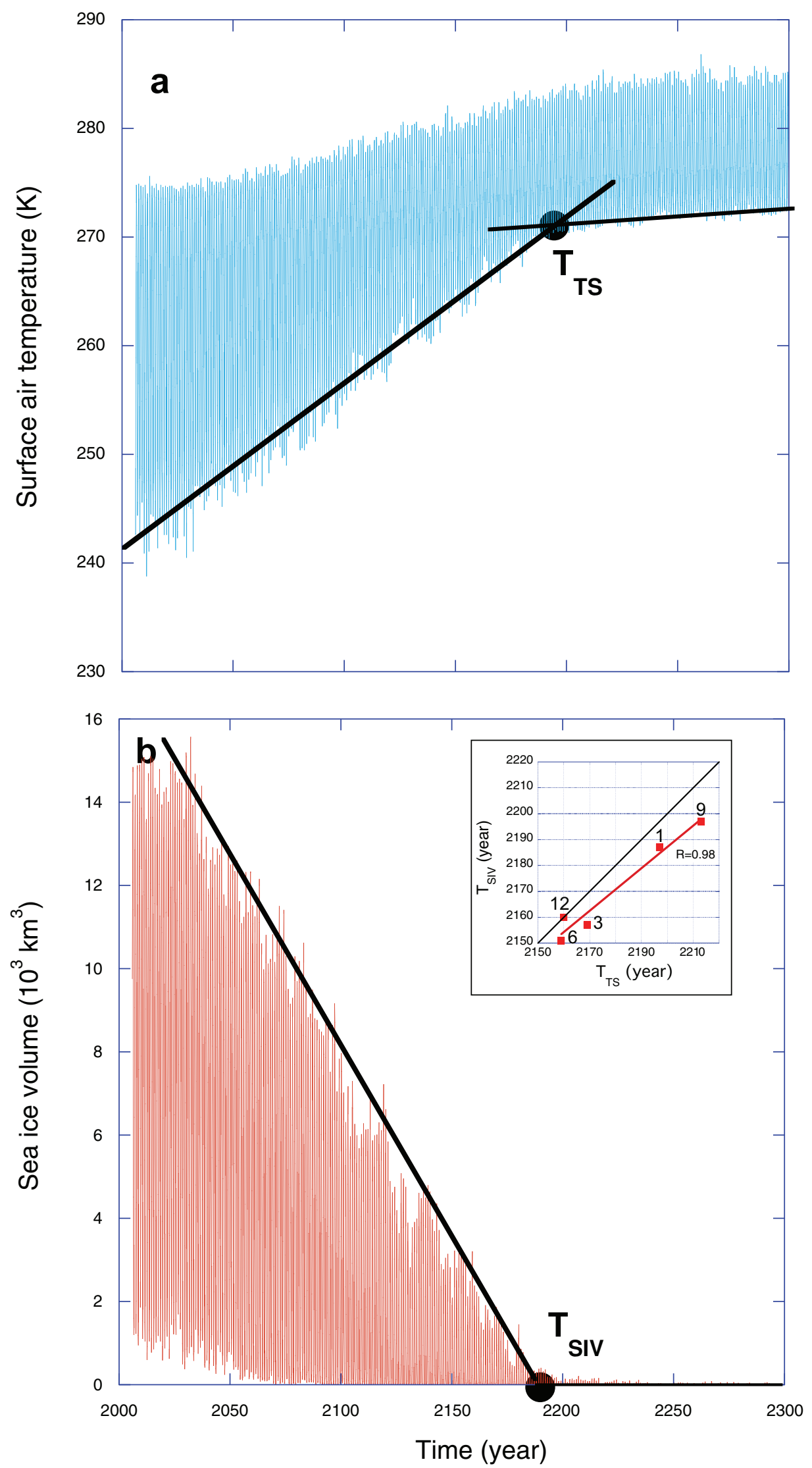

Figure $2 \mid$ Modelled seasonal temperature and sea ice changes in the Arctic $\left(70^{\circ}-90^{\circ} \mathrm{N}\right)$ for the RCP8.5 forcing (see methods). (a) Surface air temperature changes simulated by model 1 (which is used as an example), (b) Sea ice volume changes simulated by model 1 (the insert shows the multimodel correlation between the timings of the winter temperature slope change $\left(\mathrm{T}_{\mathrm{TS}}\right)$ and the sea ice volume slope change $\left(\mathrm{T}_{\mathrm{SIV}}\right)$, the slopes being represented by the linear regressions in black in (a), $\mathrm{N}=5$, i.e. only models that ran until 2300; models are designated by their number, see Methods.) 

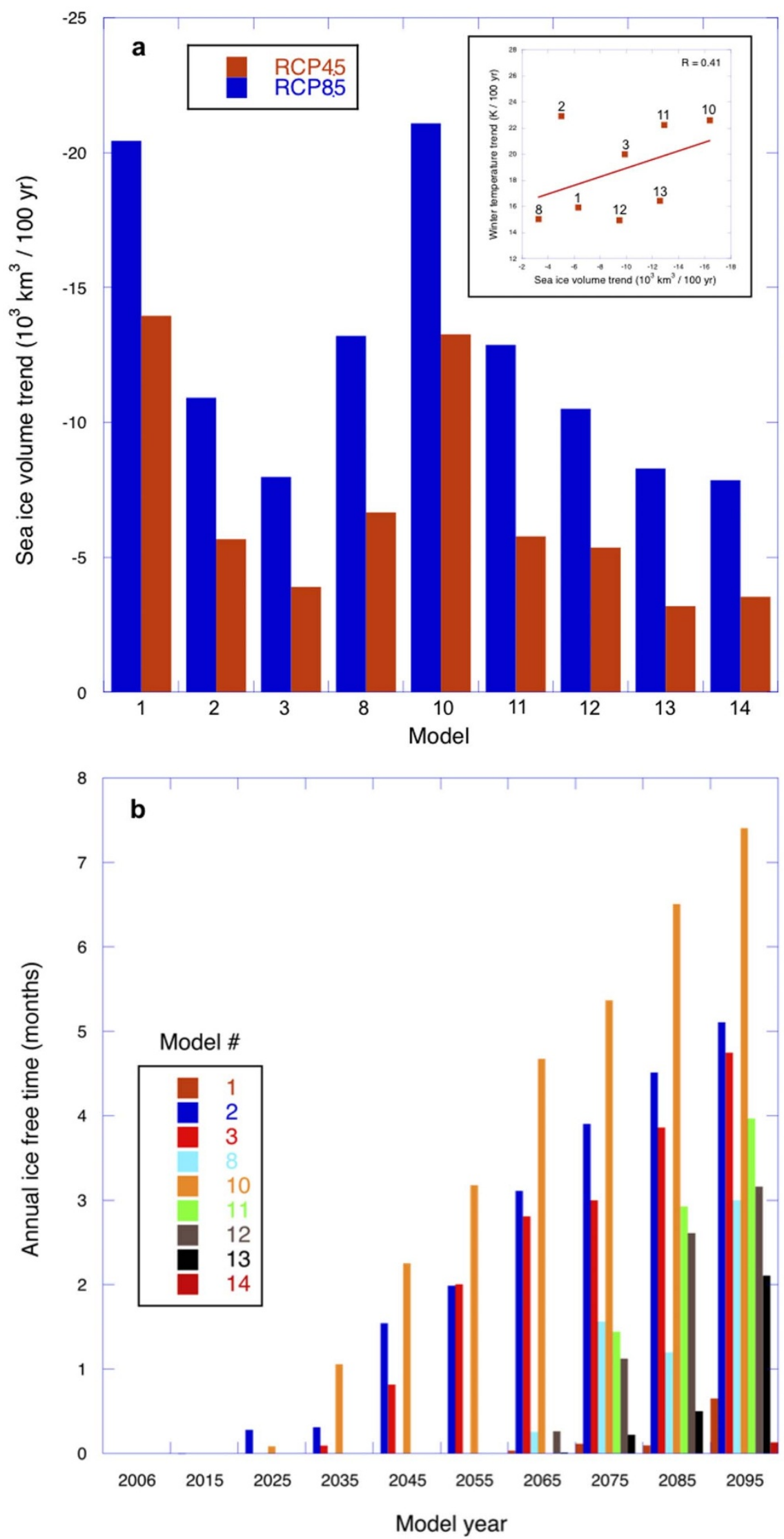

Figure $3 \mid 21^{\text {st }}$ century sea ice volume trends and changes over the Arctic Ocean (north of $70^{\circ} \mathrm{N}$ ). (a) Trends in annual maximum (i.e. March/April) sea ice volume over the $21^{\text {st }}$ century (the insert shows the trend in annual minimum temperature against the trend in maximum sea ice over the second half of the $21^{\text {st }}$ century) (both for RCP8.5), (b) Duration of Arctic Ocean ice-free conditions annually over the $21^{\text {st }}$ century under the RCP8.5 forcing $(\mathrm{N}=9$ ). The model-average duration of ice-free conditions in the decade 2090-2100 is 3.5 months. Models are designated by their number (see Methods). 

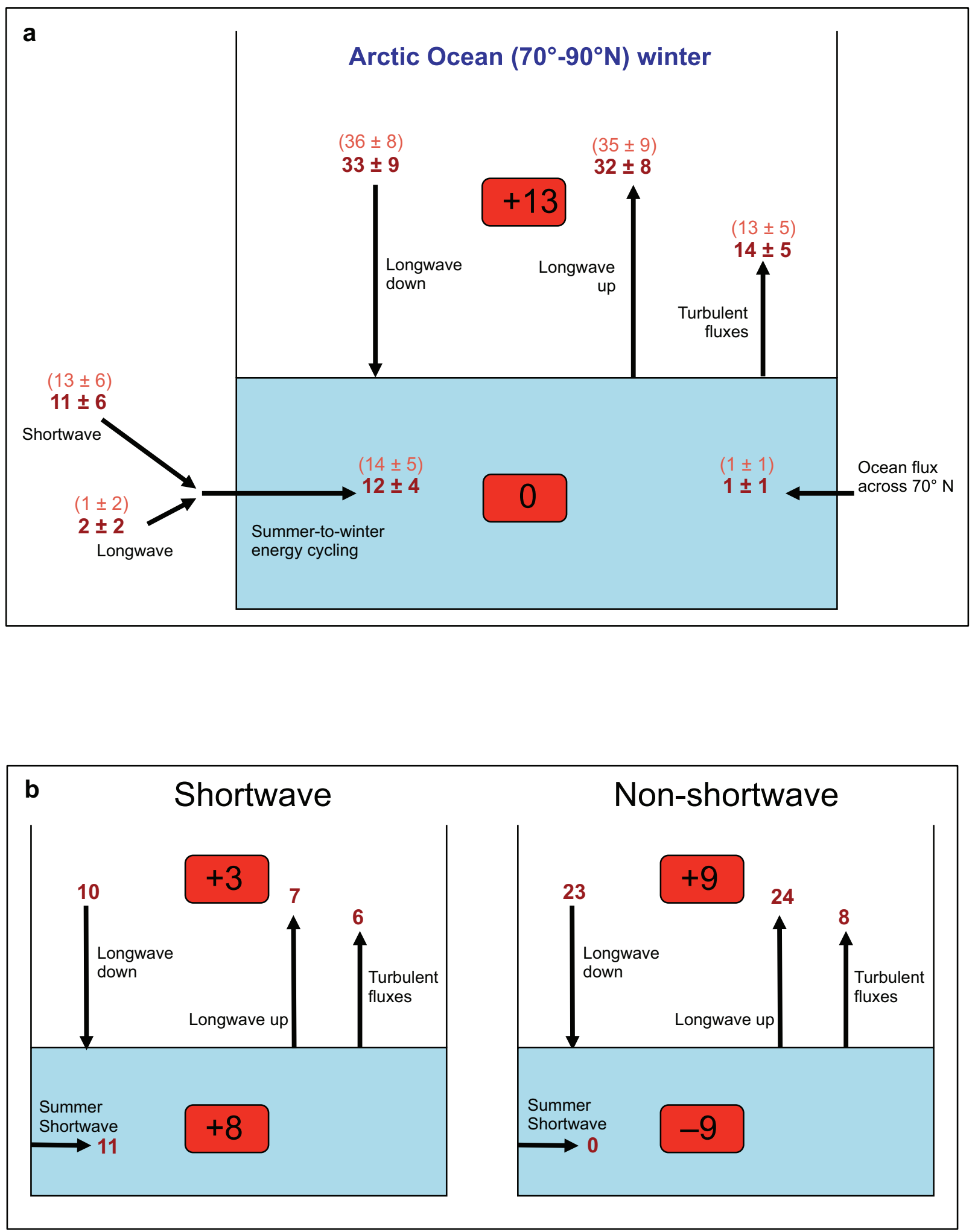

Figure $4 \mid$ Simulated $21^{\text {st }}$ century trends in seasonal surface energy fluxes over the Arctic Ocean (north of $70^{\circ} \mathrm{N}$ ). (a) Multimodel means and standard deviations of the trends in the various surface fluxes for RCP8.5 (in $\mathrm{W} \mathrm{m}^{-2}$ per $100 \mathrm{yr}$ ), $\mathrm{N}=12$ (models 1, 2, 3, 4, 6, 7, 8, 9, 10, 11, 12 and 13, see Methods). Values in brackets are means and standard deviations based on the subselection of models, namely those used in Fig. 2b (insert), i.e. models 1, 3, 6, 9, 12. (b) Same as in a but for the flux trends attributed to the summer shortwave ice-albedo feedback and the winter infrared feedbacks (left and right, respectively), $\mathrm{N}=12$. Numbers in red represent net ocean and atmosphere energy flux trends. Values are based on models 1, 2, 3, 4, 6, 7, 8, 9, 10, 11, 12 and 13 (see Methods).

According to the CMIP5 models, the major mechanism contributing to AWW is the self-contained infrared feedback (about 75\%): reduced sea ice exposes a relatively warm ocean and thereby leads to increased upwelling infrared radiation, which mainly through low-level warming ${ }^{6}$ (but also partly due to changed atmospheric water vapour and clouds) results in very strong increases in backradiation $\left(23 \mathrm{~W} \mathrm{~m}^{-2}\right.$ ), which opposes sea ice formation, yielding more open ocean, and so forth. 


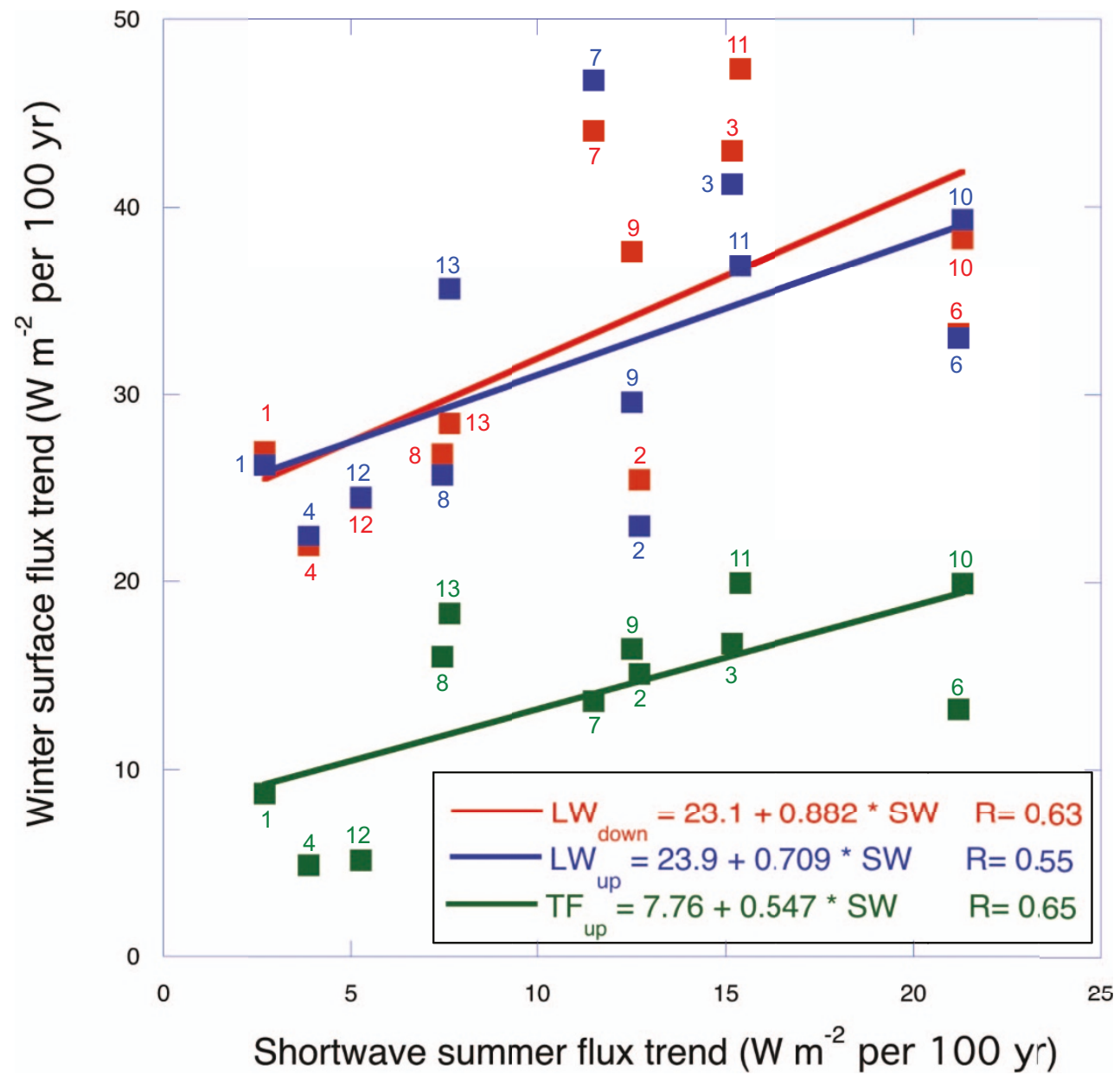

Figure $5 \mid$ Simulated $21^{\text {st }}$ century winter flux trends against summer shortwave energy flux trend over the Arctic Ocean (north of $70^{\circ} \mathrm{N}$ ).

Models with relatively modest winter surface flux trends exhibit low summer shortwave flux trends ( $\mathrm{LW}_{\text {down }}$ is the winter downward infrared radiation winter trend, $\mathrm{LW}_{\mathrm{up}}$ is the winter upward infrared radiation trend, $\mathrm{TF}_{\mathrm{up}}$ is the upward turbulent flux trend, and SW is the net summer shortwave radiation trend). The intersection with the left vertical axis represents the winter flux trends for the hypothetical situation of no ice-albedo feedback (zero summer shortwave flux trend). The lines represent the linear fits, while each symbol represents a CMIP5 model (RCP8.5). Models are designated by their number (see Methods).

\section{Discussion}

Observed current and simulated future trends of Arctic climate exhibit a strong decline in sea ice (cover and volume), as well as a very pronounced seasonally varying temperature response, with winter warming being at least four times as large as summer warming (independent of the magnitude of climate forcing). Near-surface winter atmospheric warming is conclusively linked to diminishing winter sea ice ${ }^{31}$. We find that two sea ice related climate feedbacks govern amplified AWW: 1) the ice-albedo feedback in summer through intraseasonal storage and release of energy $(\sim 25 \%)$, and, more importantly, 2) wintertime sea ice - infrared radiation feedbacks (through changes in clouds, inversion strength and moisture content) $(\sim 75 \%)$. We should note, however, that other feedbacks also contribute to AWW, in particular the meridional transports of energy in the atmosphere ${ }^{11}$ and ocean, with changed atmospheric dynamics being responsible for shifting the region of maximum warming from the subarctic regions to the Arctic Ocean ${ }^{12}$. Arctic summer exhibits only weak warming, even after summer sea ice has vanished, implying that the annual amplitude in surface air temperature decreases drastically (by more than $50 \%$ over the $21^{\text {st }}$ century). This weak summer warming can be attributed mainly to the absence of amplifying summer feedbacks. With amplified winter warming in the Arctic being one of the most outstanding features of ongoing and projected greenhouse warming, its relation to seasonal changes in Arctic sea ice helps to better understand and predict future (seasonal) changes in Arctic climate. This is imperative because of the potentially large impact on Arctic ecosystems and socio-economic developments, both of which are likely to be drastically affected in the near-future.

\section{Methods}

The use of a multimodel ensemble has been proven superior compared to using individual models in simulating the current climate ${ }^{32}$. Apparently, the average of an ensemble of modelling techniques and parameterisations provides the most accurate way to quantify climate characteristics, and it also yields an intermodel uncertainty estimate. Similarly, the use of a multimodel ensemble may well yield the most accurate estimate of climate changes and trends (and uncertainties therein). Here we use output of a variety of state-of-the-art climate models of the Climate Model

Intercomparison Project phase 5 (CMIP5) initiative to assess Arctic climatic changes. The CMIP5 initiative consists of a number of standardised model simulations ${ }^{19}$. The models that performed the simulations required for the analyses in this paper and of which the output was (for the most part) available at the time of writing are: 1. BCCCSM1.1, 2. CanESM2, 3. CNRM-CM5, 4. CSIRO-Mk3.6, 5. EC-Earth, 6. GFDL-CSM, 7. HadGEM2-ES, 8. INM-CM4, 9. IPSL-CM5A-LR, 10. MIROC5, 11. MIROC-ESM, 12. MPI-ESM-LR, 13. MRI-CGCM3, 14. NorESM1-M. Three types of CMIP5 experiments ${ }^{19}$ are used: 1) historical simulation (1850-2005) with time-varying forcing based on observations (GHG's, aerosols, solar insolation, ozone, vegetation), 2) 295-year simulation (2006-2300) with standardised forcing equivalent to $4.5 \mathrm{~W} \mathrm{~m}^{-2}$ in 2100 (RCP4.5), 3) 295-year simulation (2006-2300) with standardised forcing equivalent to $8.5 \mathrm{~W} \mathrm{~m}^{-2}$ in 2100 (RCP8.5). Note that not all simulations were done with all models (e.g. all but 5 models ran the RCP simulations until 2100 only); in case data was not present the respective model was disregarded in that specific analyses. Multimodel averages were calculated without weighing models, and we used any model of which output was available. The obvious disadvantage of the latter is that the 
various analyses were carried out with different (numbers of) models; the validity of this approach was tested in Fig. 4a, in which we performed the same analyses twice: 1) with all available models and 2) with a subset of models (those used in Fig. 2b, insert), and the differences are shown to be relatively minor, and hence this does not affect the conclusions. Where appropriate, we added the number of models $(\mathrm{N})$ used in the figure captions. All output data (surface air temperature and sea ice characteristics) are monthly means on a $1^{\circ} \times 1^{\circ}$ regular lat-lon grid. Trends are evaluated as linear regressions over the designated periods. In this paper we consider sea ice volume rather than extent (or area) because ice volume is more accurately constrained by the energetics of the Arctic than extent (for instance, when energy is being used for melt, sea ice extent may remain unchanged while sea ice is thinning).

The Arctic's (all ocean gridpoints north of $70^{\circ} \mathrm{N}$ ) seasonal energy cycle was quantified by considering the (positive downward) surface energy balance SEB $=$ $\mathrm{SW}_{\text {down }}+\mathrm{SW}_{\text {up }}+\mathrm{LW}_{\text {down }}+\mathrm{LW}_{\text {up }}+\mathrm{SH}+\mathrm{LH}$, where $\mathrm{SW}_{\text {down }}\left(\mathrm{LW}_{\text {down }}\right)$ and $\mathrm{SW}_{\text {up }}$ $\left(\mathrm{LW}_{\mathrm{up}}\right)$ are the downward and upward shortwave (longwave) radiative fluxes, and $\mathrm{SH}$ and $\mathrm{LH}$ are the surface turbulent sensible and latent heat fluxes, respectively. We calculated the sum of all positive surface energy balance: $\mathrm{SEB}^{+}=\Sigma(\mathrm{SEB})$ where the summation is over all months and all ocean gridpoints north of $70^{\circ} \mathrm{N}$ for all positive values of $\mathrm{SEB}$, and likewise $\mathrm{SEB}^{-}$for negative values of $\mathrm{SEB}$. So $\mathrm{SEB}^{+}\left(\mathrm{SEB}^{-}\right)$represents the accumulated seasonal surface energy gain (loss) of the Arctic Ocean. Both can in principle occur in all seasons, but $\mathrm{SEB}^{+}$is obviously associated mostly with the warm (summer) season, and likewise $\mathrm{SEB}^{-}$with the cold (winter) season. In Figure 4 we evaluate the individual energy balance terms averaged over all $\mathrm{SEB}^{+}$and $\mathrm{SEB}^{-}$ months and gridpoints, so as to calculate their contributions to the gain and loss periods. On average, $\mathrm{SEB}^{-}$is larger negative than $\mathrm{SEB}^{+}$is positive, with the difference to a good approximation being representative to the poleward oceanic energy transport across $70^{\circ} \mathrm{N}$ minus long-term Arctic Ocean warming (i.e. its increasing energy content ${ }^{18}$ ).

1. Holland, M. M. \& Bitz, C. M. Polar amplification of climate change in coupled models. Clim. Dyn. 21, 221-232 (2003).

2. Manabe, S. \& Stouffer, R. J. Sensitivity of a global climate model to an increase of $\mathrm{CO}_{2}$ concentration in the atmosphere. J. Geophys. Res. 85, C10, 5529-555 (1980).

3. Bintanja, R. \& Oerlemans, J. The influence of the albedo-temperature feedback on climate sensitivity. Ann. Glaciol. 21, 353-360 (1995).

4. Gillett, N. P. et al. Attribution of polar warming to human influence. Nature Geoscience 1, 750-754 (2008).

5. Serreze, M. C., Barrett, A. P., Stroeve, J. C., Kindig, D. N. \& Holland, M. M. The emergence of surface-based Arctic amplification. The Cryosphere 3, 11-19 (2009).

6. Screen, J. A. \& Simmonds, I. The central role of diminshing sea ice in recent Arctic temperature amplification. Nature 464, 1334-1337 (2010).

7. Lu, J. \& Cai, M. Seasonality of polar surface warming amplification in climate simulations. Geophys. Res. Lett. 36, doi:10.1029/2009GL040133 (2009).

8. Deser, C., Tomas, R., Alexander, M. \& Lawrence, D. The seasonal atmospheric response to projected Arctic sea ice loss in the late twenty-first century. J. Clim. 23, 333-351 (2010).

9. Higgins, M. E. \& Cassano, J. J. Impacts of reduced sea ice on winter Arctic atmospheric circulation, precipitation and temperature. J. Geophys. Res. 114, doi:10.1029/2009JD011884 (2009).

10. Graversen, R. G., Mauritsen, T., Tjernström, M., Källén, E. \& Svensson, G. Vertical structure of recent Arctic warming. Nature 541, 53-56 (2007).

11. Graversen, R. G. Do changes in the midlatitude circulation have any impact on the Arctic surface air temperature trend? J. Clim. 19, 5422-5438 (2006).

12. Zhang, X., Sorteberg, A., Zhang, J., Gerdes, R. \& Comiso, J. C. recent radical shifts of atmospheric circulations and rapid changes in Arctic climate system. Geophys. Res. Lett. 35, L22701, doi:10.1029/2008GL035607 (2008).

13. Symon, C., Arris, L. \& Heal, B. (eds) Arctic Climate Impact Assessment (Cambridge Univ. Press, 2004).

14. Chylek, P., Box, J. E. \& Lesins, G. Global warming and the Greenland Ice Sheet Clim. Change 63, 1-2, 201-221, doi: 10.1023/B,CLIM.0000018509.74228.03 (2004).

15. Serreze, M. C. \& Francis, J. A. The Arctic amplification debate. Clim. Change 76 241-264 (2006).

16. Meehl, G. A. et al. Solar and greenhouse gas forcing and climate response in the twentieth century. J. Clim. 16, 426-444 (2003).

17. Lu, J. \& Cai, M. Quantifying contributions to polar warming amplification in an idealized coupled general circulation model. Clim. Dyn. 34, 669-687, doi 10.1007/ s00382-009-0673-x (2009).
18. Crook, J. A., Forster, P. M. \& Stuber, N. Spatial patterns of modelled climate feedback and contributions to temperature response and polar amplification. J. Clim. 24, 3575-3592 (2011)

19. Taylor, K. E., Stouffer, R. J. \& Meehl, G. A. A summary of the CMIP5 experiment design. http://cmip-pcmdi.llnl.gov/cmip5/submit.html\#CMIP5_Archive (2011).

20. Koenigk, T. et al. Arctic climate change in the $21^{\text {st }}$ century in an ensemble of AR5 scenario projections with EC-Earth. Clim. Dyn. (submitted) (2012).

21. Sorteberg, A., Kattsov, V., Walsh, J. E. \& Pavlova, T. The Arctic surface energy budget as simulated with the IPCC AR4 AOGCMs. Clim. Dyn. 29, 131-156 (2007).

22. Stroeve, J. et al. Trends in Arctic sea ice extent from CMIP5, CMIP3 and observations. Geophys. Res. Lett. 39, L16502, doi:10.1029/2012GL052676 (2012).

23. Taylor, P. C., Ellingson, R. G. \& Cai, M. Seasonal variations of climate feedbacks in the NCAR CCSM3. J. Clim. 24, 3433-3444 (2011).

24. Hall, A. The role of surface albedo feedback in climate. J. Clim. 17, 1550-1568 (2004).

25. Francis, J. A. \& Hunter, E. Changes in the fabric of the Arctic's greenhouse blanket. Environ. Res. Lett. 2, doi: 10.1088/1748-9326/2/4/045011 (2007).

26. Bintanja, R., Graversen, R. G. \& Hazeleger, W. Arctic winter warming amplified by the thermal inversion and consequent low infrared cooling to space. Nature Geoscience 4, 758-761 (2011).

27. Bintanja, R., van der Linden, E. C. \& Hazeleger, W. Boundary layer stability and Arctic climate change: a feedback study using EC-Earth. Clim. Dyn. 39 (11), 2659-2673, doi:10.1007/s00382-011-1272-1 (2012).

28. Graversen, R. G. \& Wang, M. Polar amplification in a coupled model with locked albedo. Clim. Dyn. 33, 629-643 (2009).

29. Hwang, Y., Frierson, D. W. M. \& Kay, J. E. Coupling between Arctic feedbacks and changes in poleward energy transport. Geophys. Res. Lett., 38, L17704, doi:10.1029/2011GL048546 (2011).

30. Winton, M. Amplified climate change: what does surface albedo feedback have to do with it? Geophys. Res. Lett. 33, doi:10.1029/2005GL025244 (2006).

31. Screen, J. A., Deser, C. \& Simmonds, I. Local and remote controls of observed Arctic warming. Geophys. Res. Lett. 39, L10709, doi:10.1029/2012GL051598 (2012).

32. Reichler, T. \& Kim, J. How well do coupled models simulate today's climate? Bull. Amer. Meteor. Soc. 89, 303-311 (2008).

\section{Acknowledgements}

We are grateful to all members of the EC-Earth consortium for their help and support with the development of the EC-Earth climate model, the output of which is in the CMIP5 database. We acknowledge the World Climate Research Programme's Working Group on Coupled Modelling, which is responsible for CMIP, and we thank the climate modeling groups (listed in Methods) for producing and making available their model output. For CMIP the U.S. Department of Energy's Program for Climate Model Diagnosis and Intercomparison provides coordinating support and led development of software infrastructure in partnership with the Global Organization for Earth System Science Portals

\section{Author contributions}

R.B. developed the ideas that lead to this paper. R.B. and E.L. analysed the observational data. R.B. wrote the main paper, with input from both authors, who discussed the results and implications and commented on the manuscript at all stages.

\section{Additional information}

Supplementary information accompanies this paper at http://www.nature.com/ scientificreports

Competing financial interests: The authors declare no competing financial interests.

License: This work is licensed under a Creative Commons

Attribution-NonCommercial-NoDerivs 3.0 Unported License. To view a copy of this license, visit http://creativecommons.org/licenses/by-nc-nd/3.0/

How to cite this article: Bintanja, R. \& van der Linden, E.C. The changing seasonal climate in the Arctic. Sci. Rep. 3, 1556; DOI:10.1038/srep01556 (2013) 